\title{
Espaço elegíaco e representação urbana em Lêdo Ivo
}

\section{Márcio Ferreira da Silva \\ Professor assistente da Universidade Estadual de Alagoas (Uneal) e Doutorando em Literatura Brasileira do Programa de Pós-Graduação em Letras e Lingüistica da Universidade Federal de Alagoas (Ufal), sob a orientaçāo da Profa.. Dra. Vera Romariz Corrêa de Araújo.}

Resumo: Estudo sobre o espaço literário e a representação urbana na fiç̧ão de Lêdo Ivo. A relaçāo entre a forma e a linguagem literárias impōe uma narrativa que explora a descrição negativa, com tom elegíaco. Essa forma, que se apropria de desfiguraçōes de ambiente e de espaços literários, interfere na representação da cidade como elemento ficcional na contemporaneidade.

Palavras-chave: espaço; forma; representação literária; Lêdo Ivo.
Resumé: II s'agit d'une étude sur l'espace littéraire et la représentation urbaine dans la fiction de Lêdo Ivo. Le rapport entre la forme et le langage littéraires impose un récit qui exploite la description négative, d'un ton élégiaque. Cette forme, qui s'approprie les défigurations de l'ambient et des espaces littéraires, intervient dans la représentation de la ville en tant qu'élément fictionnel dans la contemporaneité.

Mots-clés: espace; forme; représentation littéraire; Lêdo Ivo 


\section{.}


A obra narrativa do escritor alagoano Lêdo Ivo faz da representação literária do espaço urbano uma possibilidade de transgressão. Essa capacidade transgressora no romance é captada pelo movimento entre narrador, personagem e espaço. Dentro desse universo, o autor cumpre a metamorfose anunciada, visto que a cidade configura na contemporaneidade momentos de descentramento de sujeito e desfiguração da cartografia metropolitana, marcado pela decomposição do espaço narrativo tradicional.

Ledo Ivo não apenas flagra a cidade natal, mas faz uma representação singular da planta urbana de Maceió; sua composição narrativa e sua linguagem se fundem em um ato sincrônico em que a primeira traça poeticamente um canto elegíaco à cidade e a segunda aproveita-se do canto de morte para dar à palavra um requinte estilístico somente propício à ficção.

Há, na maioria das narrativas ledianas, uma apropriação de sentimentos mórbidos como no episódio da raposa que é "assassinada" no primeiro capítulo do romance Ninho de cobras'. Imagens que se apresentam na representação da cidade provinciana de Maceió, configuradas por um narrador que, astuto como uma raposa, deixa inquietações no leitor: o que faz uma raposa no centro de Maceió? O que o animal espreita? Há uma relação entre a raposa e a cidade ou a raposa e as personagens? Se há um sentido de contemporaneidade dado pelo narrador à presença da raposa, por que o "estranhamento" dos habitantes da cidade? A presença da personagem-raposa confere à narrativa um tom de elegia urbana, singularidade presente na maioria das obras de Lêdo Ivo. O estilo lediano permite-nos inferir, também, um conceito de lugar do escritor alagoano na narrativa brasileira. Nosso objetivo é analisar de que maneira a forma romanesca evidencia os estratos culturais na contemporaneidade, aqui delimitada na análise dos romances As alianças? (1947) e Ninho de cobras (1973).

O sentido que estamos dando ao termo elegia está parcialmente ligado ao conceito clássico: elegiaé um canto de louvor à morte. Inicialmente definida pelo metro
'IVO, Ledo. Ninho de Cobras. Rio de Janeiro: Topbook, 1997. A partir de agora, as citações referentes a esta obra de Lêdo Ivo aparecerão no texto indicadas pela abreviatura $\mathrm{NC}$, seguida do número da página.

${ }^{2}$ Cf. IVO, L. $A s$ alianças. 3. ed. São Paulo: Ed. Parma, s.d. (Imortais da Literatura Brasileira). As citações referentes a esta obra de Lêdo Ivo serão indicadas pela abreviatura AA e pelo número da página. 
${ }^{3}$ Segundo Soares (2001, p. 32), "O termo elegia vem do grego elegeia e refere-se a formas orais que exaltavam o luto e a tristeza. Há uma relação também com o termo armênio elegn, elegneay (provavelmente dos escritos helênicos) que significa bambu ou flauta de bambu, cuja função era acompanhar "cantos lutuosos". específico, chamado metro elegíaco, a elegia passou a designar uma forma poética que se caracterizou bem mais pelo assunto: a tristeza dos amores interrompidos pela infidelidade ou pela morte. Assim, a elegia é uma produção poética de canto doce, afinado, com tons de tristeza e de morte, mantido, na representação artística de Lêdo Ivo, na linguagem mormacenta das areias brancas que cobrem os cemitérios de Maceió. A "um lírico elegíaco" é dada a capacidade de criar a palavra sob tons de lamento e de musicalidade poética. Uma música composta, portanto, em louvor à morte do dia e da noite. ${ }^{3}$

Embora a cidade esteja presente no olhar com que Lêdo Ivo descreve e observa o campo empírico a sua volta, o autor de Mar oceano (1987), na definição de Ivan Junqueira (2004, p. 27), "é, acima de tudo, um lírico elegíaco", um escritor que, aproveitando-se do lirismo natural das palavras, explora a descrição negativa do espaço urbano como se a forma literária assumisse, a todo o momento, um tom de decomposição do espaço narrativo urbano, cuja cartografia tende para uma decomposição, uma desfiguração da imagem estereotipada da cidade. Por isso, a linguagem espacializada assume tons de categorias negativas, diante da palavra lediana, porque ele se nutre delas. "É minha obra que me cria", diz Lêdo Ivo, na obra lírico-biográfica Confissões de um poeta (2004).

Podemos perceber que Lêdo Ivo produz um texto ficcional elegante e pungente. O autor de Plenilúnio (2004) impulsiona a deflagração do espaço narrativo negativo, explorando a cartografia urbana degradada. Despreocupado com a classificação e nomenclatura de sua produção artística, Lêdo Ivo constrói a ficção nos pilares da cidade dicotômica, cuja mistura de forma impõe sobremaneira os estratos culturais que mantêm a cidade em movimento. Nesse sentido, entendemos que o trabalho artístico deste escritor alagoano corrobora a tendência literária de construir uma forma ficcional híbrida em consonância com a forma cultural. Diante disso, acreditamos que Lêdo Ivo explora, também, a forma elegíaca porque o canto de morte é o mote para construir uma cartografia negativa que re- 
presente a cidade de Maceió. Por isso, formas artísticas como a ode e a elegia ganham plasticidade na descrição negativa que sustenta a ficção de Lêdo Ivo. A forma elegíaca, no nosso entendimento, tem uma ligação bem substancial com a produção artística deste escritor alagoano, estando relacionada à proposta primeira do escritor de traduzir seu lugar sob o signo da negatividade, como nos ensina Leyla Perrone-Moisés (1985); outro aspecto está na forma pela qual a ficção adquire multiplicidade de vozes presentes no discurso do narrador.

O escritor alagoano constrói sua temática em torno do lamento e do pranto à morte. Essa manifestação se dá, quase sempre, nos signos de que o artista se apropria, extraídos da geografia urbana referencial: cemitérios, túmulos, mortalhas são símbolos lingüísticos reforçadamente carregados de imagens memorializadas na lembrança e saudades daqueles que partiram.

Minha pátria é a mão do mendigo na manhã radiosa. São os estaleiros apodrecidos

e os cemitérios marinhos onde meus ancestrais

[tuberculosos e impaludados

não param de tossir e tremer nas noites frias ${ }^{4}$.

Essa marca, quase sempre sensível, áspera e triste, faz de Lêdo Ivo um flautim poético que toca melodias de palavras soturnas, enamoradas com as imagens das lembranças dos antepassados e da morte necessariamente presente. No capítulo "O roupão", do romance Ninho de cobras, por exemplo, a personagem encontra-se enferma num quarto de hospital. O narrador explicita a causa pela qual a mulher estava ali. "A mulher fora internada para tratar de um esquentamento e um cancro mole" (NC, p. 60), mas a forma narrativa lediana desarticula o enunciado para mostrar um narratário implícito que demonstra a conseqüência vital da existência da personagem. "Na verdade, era como se estivesse podre" (NC, p. 60). O discurso agora se impregna de um canto de morte tão marcante no autor analisado.

Há um antagonismo quanto à forma e ao conteúdo nos gêneros clássicos odee elegia-e Lêdo Ivo incorpo-
${ }^{4}$ Versos do poema "Minha Pátria", de Lêdo Ivo, que faz parte do livro Plenilúrio, 2004, p. 15. 
ra essa tensão advinda dos contrários, pois representou a Poesia de 45 com o livro Ode e elegia (1945). Relacionada ao canto, como a elegia, mas diferente no tema, a ode (do grego oidê, canto) é uma forma lírica, construída simetricamente (FERREIRA, 1986): um canto à vida. Diante desse universo lírico, o poema odilíaco representa o canto alegre e as formas de agradecimento aos deuses da Antigüidade. Lêdo Ivo representa poeticamente a forma poética elegíaca porque reconhece que a valoração clássica remete-nos ao conceito mimético aristotélico; entretanto os escritores dessa geração, sabendo que "os modernistas desprezaram as convenções miméticas" (FERNANDES, 2003, p. 109), não buscavam uma uniformidade para a forma poética, mas um compromisso estilístico e estético com o tema e a forma, tão discutido pelos modernistas de 22 . No entanto, a busca por um equilíbrio poético não absorve da poesia lediana seu valor estético, mesmo quando, segundo Teles (2004, p. 9),

[Lêdo Ivo] soube assumir desde cedo a liderança de um grupo de poetas que, em torno de 1945 e sob influências de leituras estrangeiras, acabaram transformando em matéria pessoal as concepções poéticas e retóricas que alguns (não todos) modernistas haviam inicialmente abandonado.

\section{Representações culturais e espaço urbano}

Toda a expressão humana parte, necessariamente, de uma forma cultural gerada na memória. Nossa mente alimenta-se de ações e imagens captadas do passado e nossas escolhas podem ser, via de regra, escolhas impostas, manipuladas por gostos ideológicos gestados nas relações sociais. É fácil perceber, então, a linha contínua entre o caráter social e o caráter cultural da sociedade. Ainda que esses dois aspectos apresentem-se em processo cíclico sociocultural, é necessário atentar para o fato de que a temática cultural nos estudos literários tem colocado em discussão elementos da representação literária incapazes de serem atribuídos aos estudos de uma crítica unicamente sociológica. 
A necessidade de lograr à cultura um lugar delimitado para o pensamento estético na literatura reside, parcialmente, na complexidade do mundo moderno. As tensões modernas traduzem o sujeito ceifado de multiplicidade, dividido entre estratos culturais em movimento. A valoração dos costumes locais, por exemplo, dá à existência humana relação aberta para a tradição. Manter a organização colonial nas cidades, como assegura Angel Rama (1985), no letramento e no registro da palavra letrada, ou se identificar com as formas culturais existentes no presente, pode, à primeira vista, representar uma configuração de uma ordem ideológica que quer dizer-se hegemônica, porque a ideologia sustenta os ideais de ordem e de poder. Talvez por isso a representação cultural busque alternadamente o reconhecimento no deslocamento dos estratos culturais, haja vista que há, quase sempre, uma força maior que se sobrepõe sobre outra menor. Pode não parecer, mas vestimos a roupa que nos parece ideal? Ou aparentamos vestir uma roupa que nos é imposta?

Assim como nos identificamos pelas diversas formas pelas quais nos expressamos, as formas culturais dizem aquilo que somos. Falar, dançar ou vestir são vestígios dos estratos culturais pelos quais identificamos nossa forma particular de cultura. Tal particularidade não significa aqui o isolamento, mas elementos adquiridos de nossos ancestrais e gerações passadas. O particular, na verdade torna-se coletivo, porque a relação com o mundo moderno instaura ou porque carregamos desde a gestação dependência cultural com um Outro. Afinal, é a coletividade que é o todo de nós mesmos e não a individualidade. A relação com o Outro traz-nos dependência e reflexo, como nos ensina Hall apud Derrida (2003). Vivemos em relação e na projeção ao Outro. É com esse Outro que nos construímos. Isso não é, portanto, um conflito, todavia é o reconhecimento de que a coletividade necessita de um ser cada vez mais ontológico, fortalecido pela incapacidade de ser uno, mas híbrido.

Esse pensamento reforça a idéia de que fatores culturais são representados na forma literária na modernidade. Nesse sentido, como nos diz Luiz Costa 
Lima (2003), a modernidade convive livremente com oespaço tumular, marcado pelo abandono do estilo homogêneo, gestado pelos românticos, para identificar-se com a palavra deslocada, entrecortando a linguagem sublime e o universo simbólico do desprezível, do descaso e da infâmia social. "A mistura de estilos manifesta, pois, a modernidade”, assegura Lima (2003, p. 135). Daí porque nas decomposições da rua parisiense baudelaireana "formigam as contradições sociais" (ibidem, p. 123) e o espaço da rua é o espaço do encontro com as diferenças, com o Outro, com o estranho.

No tocante à narrativa, Angel Rama (1974) afirma que todo escritor fala de sua comunidade lingüística, criando um processo de transculturação narrativa. Remedi (1997) acredita que esse conceito reporta à idéia de que as cidades na América Latina formam o trânsito entre centro e periferia, local e global, devido tanto ao processo de colonização quanto ao projeto capitalista de economia globalizada. Todavia esse trânsito cultural forma o perfil comum das expressões literárias entre uma cultura e outra. Não se trata aqui de um processo de aculturação, haja vista que há um movimento simétrico entre as culturas. Ou seja, não há a eliminação da cultura do Outro, como faz a assimilação acultural, mas o sentido de assimilar outra cultura sem, ao mesmo tempo, desvincular-se da sua. O presente nos dá um sentido de cultura, cujos valores caem sobre condições e movimento de relações consumistas; políticas e econômicas, que se apresentam em choque com as formas culturais da contemporaneidade. De um lado, a cultura urbana instaurou a tentativa de deslocar os estratos culturais para a periferia social, acreditando no apagamento da tradição; de outro, percebe-se que paralelamente ao sentido de "cultura global", a "cultura local" permanece instaurada, porque a mobilidade cultural possibilita o trânsito entre o passado e o presente.

Em meio às tecnologias eletrônicas, na compreensão de Néstor Garcia Canclini (1998, p. 290), "o homem se torna cliente", pois há uma necessidade de instituir um público consumidor cada vez mais voraz e obediente. A cidade revela-se, pois, na composição desse uni- 
verso dicotômico em que as diferentes expressões culturais preexistem em meio ao conturbado mundo moderno. Assim, o mercado capitalista "oferece" ao consumidor uma imagem construída a partir da cidade. Esta evidencia na consciência do homem uma idéia cultural de locale de lugar. Os termos são definidos como "espaço ocupado". Portanto, o significado dilata-se nos macrotopos que formam, juntos, a cartografia da cidade. Cada termo tem, pois, componentes de espaço urbano. O crescimento do espaço urbano põe em confluência as linguagens descontínuas, geradas pela velocidade e pela dinâmica de imagens locais. A representação da cidade passa a ser "construída" sob a atmosfera de culturas que sobrevivem sob o reflexo da diversidade. Canclini (ibidem, p. 285) diz que "a expansão urbana é uma das causas que intensificaram a hibridação cultural".

O estudo de Craveiro Costa (1981) sobre a formação dos bairros populares em Maceió, a partir do governo republicano, registra, por exemplo, a criação de espaços sociais que definem o caráter sociocultural da cidade. Os bairros de Jaraguá e Bededouro ostentam a expansão econômica e social no início do século XX. Assim, o café "Ponto Central", na rua do Comércio, o Clube Fenix Alagoana, o Teatro Deodoro são sinais de urbanidade. A rua é a fotografia urbana aos olhos dos habitantes, mas, segundo Manoel Diégues Júnior (1939, p. 67), “em Maceió só nos fins do século XIX é que começa a rua a armar-se de mais importância". Muitos preferiam o espaço da casa porque, na tradição de nossos antepassados, muitos acreditavam que o contato com a rua era para a "ralé". Diante da cidade, a rua é o espaço da microscopia cuja dimensão é seguramente delimitada pelo artista. O espaço público da rua torna-se, então, o local do deslocamento, do estranhamento e da solidão. Vejamos o que diz Lucas apud Eduardo Yazigi (2001, p. 176):

[A rua] é o lugar do não-lugar do caminhar, pois caminhar é não ter lugar. Na calçada realiza-se o universal, o encontro do outro, do diferente [...] Fora dos espaços fechados e de nossos iguais, dos 
${ }^{5}$ IVO, L. Use a passagem subterrânea. 2. ed. Rio de Janeiro: Record, 1984. A partir de agora, os textos relativos ao conto em análise serão referenciados com a abreviatura UPS. valores do grupo, na rua somos submetidos ao encontro do lugar e da experiência que realmente realiza nosso sentido coletivo ou, na pior das hipóteses, funciona como cartilha [...] Nela [na rua], sem identidade, somos frágeis.

É na rua que a personagem, tentando atravessar para o outro lado da avenida, depara-se com o subterrâneo, mas esse espaço do subsolo, espaço de decomposição, marca a imersão no mundo interior das personagens. O encontro sigiloso evidencia que o caminho a ser seguido muitas vezes ampara-se na desordem, no descentramento cultural da personagem. Veja-se, por exemplo, o adultério de José, em As alianças, ou de Alexandre Viana, em Ninho de Cobras, ou ainda o (des)encontro na passagem subterrânea, no conto "Use a passagem subterrânea" ". Nesse momento, tudo mostra a decomposição da visão que o narrador-personagem faz do espaço urbano e da amada. Para o professor Serafim Gonçalves, personagem de Ninho de Cobrase para Jandira, de As alianças, a rua evidencia o encontro com um Outro.A descrição elegíaca lediana sempre impõe uma imagem representativa do amante a partir do mar mormacento; a rua estreita e torta, enfim, da cidade.

Como podemos perceber, a modernidade faz o deslocamento do homem para a rua e para a descoberta do labirinto das cidades. O movimento vertiginoso, muitas vezes desarticulado, do espaço urbano evidenciou entre as décadas de 60 e meados dos anos 80 do século passado, em Maceió, o surgimento de lojas de departamentos que marcavam um novo espaço de consumo. Remedi (1997, p. 118) diz que "el lugar central de la vida cultural de este fin de siglo lo ocupan, por supuesto, las nuevas calles, plazas y lugares de paseo y de reunión que son los shopping centers, puntos de actividad social y cultural que compiten y desplazan a los antiguos espacios públicos, hoy degradados e semi-abandonados". As diversas formas sociais e econômicas refletem uma necessidade de organização identitária com o espaço em movimento. Em Ninho de cobras, a rua tem uma representação que anuncia uma descoberta para 
o narrador. Diante do movimento dos transeuntes, o narrador descobre-se no meio da multidão. É o narrador que anuncia a Alexandre Viana a novidade:

Era feito só e exclusivamente de palavras - e o povo falava palavras. Até as pedras das ruas de Maceió eram feitas de palavras. Alexandre Viana comia palavras, dormia palavras, trabalhava palavras. E se sentia mais solitário do que nunca, como a própria arma que se desenhava diante de seus olhos se fosse converter numa palavra. (p. 55)

A cultura urbana projeta-se com um sentido dicotômico existente nas caracterizações dos espaços cosmopolitas. A cidade constrói seus estratos culturais e sociais na composição urbana representada nos rituais presentes nas ruas, nos bairros ou nas favelas, formando a paisagem cultural da cidade. Por isso, ratificamos o pensando crítico de Canclini (1998), de que os estratos culturais entrelaçam-se o tempo todo, não abolindo a possibilidade de representações de culturas estarem existindo em associações de bairro, na periferia e na escola. A fórmula hegemônica que eclode na cidade representada nos romances de Lêdo Ivo reforça a forma descritiva elegíaca imposta na caracterização de Maceió e o romance cumpre, na modernidade, uma aparente desconexão crítica da linguagem com a realidade. Desde Mário de Andrade, passando por Guimarães Rosa e Clarice Lispector, a narrativa saqueia imagens que se confundem: o mundo indígena e a sociedade urbana; as tradições afro-brasileiras e experimentação oral da linguagem; a personagem feminina e a introspeç̧ão memorialista da linguagem. Lêdo Ivo interpela os signos da urbanidade e, por isso, sua narrativa brota do descompasso das ações periféricas. Há no romance Ninho de cobras um divisor estritamente cultural: a representação do homem alagoano utilizando a força em um sentido arbitrário de justiça, sentido mantido no romance na representação do "Sindicato da Morte" convivendo paralelamente com a passagem e a morte da personagem-raposa. 


\section{A narrativa elegíaca nos labirintos da cidade}

O pensamento crítico da narrativa contemporânea, principalmente a partir da década de 60 do século passado, vem se preocupando com a problemática que influenciará a vida do romance na década seguinte. $O$ mundo passa a conviver com o trânsito entre o local e global, com o controle hegemônico dos países ricos na tentativa de unificar ações e tradições culturais dos povos do mundo. A economia passa a ser a justificativa de infiltração das idéias e maneiras de vida local para torná-las formas únicas de expressão, como se o mundo fosse um universo sistematicamente elaborado e direcionado para um único sentido. $\mathrm{O}$ saber individual muitas vezes é dizimado em favor do consumo e do "desenvolvimento" das cidades. Tem-se a impressão de que as coisas são "novas" ou transformadas, mas o mundo empírico apresenta-se diluído, em virtude do avanço econômico imposto pelas economias do Primeiro Mundo. Sabe-se que um dos locais em que esse processo de redimensão se apresenta de modo tenso é a cidade.

Em Lêdo Ivo, as tensões culturais são representadas na forma literária na maneira pela qual o narrador descreve o ambiente, como podemos perceber no confronto entre as identidades culturais fixas e móveis na modernidade. Assim, percebe-se que Jandira e José, no romance As alianças, são estranhos no interior de um mesmo ambiente, pois eles compõem um universo que se estabelece nas confluências entre o local, o centro e o global.

Era estranho que Jandira, agora, se resumisse a uma série de movimentos quase imperceptíveis. Os cabelos lavados pela claridade do sol, as pernas avançando lentamente, como se os pés evitassem pisar em lugares molhados, as costas ligeiramente inclinadas, ela ia se distanciando. $\mathrm{Na}$ paisagem, onde o mar, os montes, o telhado do casario e as vegetações se estendiam, Jandira era um ponto miúdo. (AA., p. 68)

Diante disso, há uma incessante procura do impossível centramento, evidenciando que as alianças po- 
deriam manter a provável ordem estável da condição social das personagens confirmada pela tradição, mas há, no entanto, nas condições de sobrevivência dos protagonistas, a imagem do mar cuja simbologia sugere a possibilidade de transgredir a vida rotineira - estável - para a janela do mundo - mobilidade.

Lêdo Ivo propõe uma ampliação na lente do binóculo que olha a cidade. Ele reconhece nas relações entre objetos e imagens a capacidade de traduzir em várias formas o mundo e o ser humano. Diante dessas escolhas, há na narrativa uma necessidade de evidenciar o deslocamento de personagens que se movimentam em espaços desfigurados, com forte apropriação de descrições elegíacas; logo o escritor, através da voz narrativa, dá à palavra as instâncias que se confundem com o momento cultural, fragmento do mundo contemporâneo.

Para a representação ficcional, Lêdo Ivo apropriase da paisagem empírica da capital alagoana para atribuirlhe tons elegíacos, que se mesclam ao amor clandestino e à saudade dos mortos, como no encontro secreto entre $o$ bacharel e uma mulher casada ou a descrição do cemitério no decurso do enterro de Alexandre Viana no romance Ninho de cobras. A todo o momento, o escritor nos diz que há um lugar todo seu: a cidade, uma cidade, qualquer cidade, um lugar marcado pela maresia e pela ferrugem dos navios apodrecidos. Um lugar a que ele, através de imagens simbólicas, pode retornar a qualquer hora e a qualquer momento, porque os limites de fronteira são de mobilidade, como quando o narrador apresenta as personagens em seus espaços de negatividade nos dois romances citados. Na verdade, ambos apresentam representações espaciais que propõem espaços negativos móveis como a imagem do mar, por exemplo, em que a paisagem edulcorada foge à cena para dar lugar à imagem dos "cadáveres dos marujos mortos de febre amarela" que "tinham sido desembarcados e enterrados na praia que, com os tempos, se converteu numa avenida, suprimindo-lhes os túmulos" (NC., p. 13).

A posição autoral dá ao escritor uma apropriação 
constante da cidade e da relação desta com a ação e movimentação das personagens na narrativa. pois a linguagem de Lêdo Ivo ora se reveste da descrição dos movimentos dos transeuntes nas ruas, das composições elegíacas dos lugares, como praças sombrias, avenidas que demarcam os limites da cidade; automóveis perdidos na noite imensa e túneis que levam a outra dimensão; ora se contempla em "coisas turbulentas", dentro e fora do ambiente urbano, vividas pelas personagens diante das "sobras de um outro mundo", como observamos nas duas cidades descritas por Ángel Rama (1984).

Podemos observar que, no conto "Use a passagem subterrânea", a decomposição do espaço elegíaco narrativo surge como um pedido, pois a passagem levaria a personagem a um encontro amoroso; por isso ela justifica sua presença naquele lugar. Todavia, quem ama precisa encontrar-se em um túnel escuro? O encontro já revela o tom elegíaco da narrativa. "Estava do lado do sol e da vida, e séculos inda vazios juncavam meu futuro. E era simples explicar tudo isso: eu amava" (UPS, p. 118). Mas esse amar foge dos ideais românticos e sentimentais, privados pela subjetividade do ser. Para Lêdo Ivo, esse sentimento existe no avesso do mundo, ou seja, no duelo entre viver $x$ morrer; amor $x$ ódio; verdade $x$ mentira: um jogo da forma antitética moderna. Isso faz que as dimensões antitéticas ledianas busquem situações do movimento barroco para montar o cenário do sujeito.

O encontro no espaço negativo do romance é o motivo principal da narrativa de Lêdo Ivo, como já afirmamos anteriormente. Entre o encontro e a traição, há um espaço elegíaco que se apresenta como o motivo da ação na narrativa; por isso, há necessidade de vivenciar os momentos imediatos cuja solução é apresentada diante da passagem subterrânea ou da presença do intruso na noite mormacenta. Assim, a representação da cidade é mantida na cumplicidade do jogo urbano, juntamente com as personagens. Bakhtin (1993) afirma que há, na construção da forma literária, a categoria do "motivo do encontro" em que o autor explora o elemento descritivo. "Eu sabia o 
que lhe custara aquele encontro: a astúcia, as artimanhas, os fingimentos, a discrição, o medo contido" (UPS, p. 119). $\mathrm{Na}$ verdade, essa atitude da criação artística se mantém no alargamento do espaço urbano para focar o delineamento da ação na microscopia representada pela passagem subterrânea. A personagem percebe que a visão da passagem subterrânea constrói em si um estranhamento: a cidade não apenas cresce verticalmente, mas também em sentido oposto, no subterrâneo, no submundo. Lugar em que se dá o encontro com o inesperado, o desejo proibido, a traição. Os seres humanos assim como os espaços urbanos compõem um mundo que se metamorfoseia constantemente, logo os instantes devem ser observados e representados como processo de depuração inevitável do ser social nas grandes cidades.

A passagem subterrânea só é atravessada por aqueles que amam. "Todos, os preguiçosos ou os açodados, atravessavam as pistas cruzando o asfalto reluzente. E a explicação era simples, matemática: ninguém usava a passagem subterrânea porque ninguém amava" (UPS, p. 120). Essa conclusão do narrador-personagem corrobora o instante em que a cidade lhes apresenta o "buraco de cimento" como o local para consumação do amor instantâneo, secreto, preso no subsolo da cidade.

O espaço romanesco urbano é, pois, a própria vida das descrições que flagram o momento submerso e o mergulho em busca do instante das personagens. "Somente nós ficávamos ali, porque somente nós estávamos amando na imensa cidade medusada pela pressa e lambida pela fuligem" (UPS, p. 119). Todos os habitantes convivem com a presença medusada da cidade que transforma tudo em pedra, como Medusa que, na mitologia grega, transformava em pedra, sob a invasão do olhar, os homens que ousavam enfrentá-la. Na verdade, a cidade metafórica representada nos diz, pela voz do narrador, que essa metamorfose não se dá apenas no lugar e nas coisas, mas também nas personagens. As ações dos homens nos centros urbanos são transformadas em pulsões que explodem na microscopia do espaço, como a passagem subterrânea em 
que se efetiva o encontro, como a presença da personagem-raposa no centro de Maceió ou, ainda, como a paisagem urbana criada por Jandira. O amor ocupa o espaço elegíaco e se transforma em gozo, prazer imediato, porque é o instante do prazer instantâneo que busca o sujeito moderno. "Ninguém viria molestar-nos. O mundo transfluía em grito e suor, em estridor e saliva, mas longe dos ladrilhos que nem sequer refletiam nossas figuras anônimas e amorosas" (UPS, p. 121). E como os automóveis que passam velozmente, o motivo do encontro se mantém na velocidade do fluir das horas. Sem palavras, o narrador-personagem enuncia as ações que são representadas pelo jogo metafórico dos espaços elegíacos urbanos. O silêncio do instante instaura na temporalidade o espaço em decomposição, transformada na sexualidade do encontro na passagem subterrânea. Afinal, os encontros dos personagens na passagem subterrânea e do professor Serafim Gonçalves com o marinheiro norte-americano formam os espaços elegíacos, pois cada encontro se movimenta na cidade como se esta lhe desse forma e sentido. Assim, a cidade thes deu o ingresso para adentrar um mundo incomum em que a espacialidade filtra as personagens na decomposição elegíaca de suas próprias ações.

Nesse sentido, a narrativa lediana representa o (des)encontro humano no espaço elegíaco da modernidade. O sujeito moderno é transformado em um ser instantâneo, cúmplice dos espaços da cidade, presente nos romances $A s$ alianças e Ninho de cobras e no conto "Use a passagem subterrânea". Isso é percebido porque a cidade é flagrada em um processo de decomposição do espaço narrativo, cuja descrição o decompõe na "grande boca de cimento rasgada no chão", que esperava aquele homem e aquela mulher para o encontro marcado no olhar, onde "as abelhas cantavam, no ouro da tarde imensa” (UPS, p. 121). 


\section{Referências}

BAKHTIN, M. Questões de literatura e de estética: a teoria do romance. Tradução Aurora Fornoni Bernardini et al. 3. ed. São Paulo: Unesp/Hucitec, 1993.

BOSI, A. Literatura e resistência. São Paulo: Companhia das Letras, 2002.

CALVINO, I. Cidades invisíveis. São Paulo: Companhia das Letras, 2002.

COSTA, C. Maceió. 2. ed. Maceió: Sergasa, 1981.

DIÉGUES JÚNIOR, M. Um século de vida social. In:

Maceió: cem anos de vida da capital. Maceió: Casa Ramalho Editora, 1939.

FERNANDES, Mi L. O. O tecedor do vento: o narrador em Roberto Drummond. In: MARCHEZAN, L. G. \& TELAROLLI, S. (org.). Faces do narrador. Araraquara: Laboratório Editorial/FCL/UNESP; São Paulo: Cultura Acadêmica Editora, 2003.

FERREIRA, A. B. de H. Novo dicionário Aurélio da língua portuguesa. Rio de Janeiro: Nova Fronteira, 1986.

HALL, S. Da diáspora: identidades e mediações culturais. In: Liv Sovik. Tradução Adelaine La Guardia Resende. [et al]. Belo Horizonte: EDFMG; Brasília: Representação da UNESCO no Brasil, 2003.

IVO, L. As alianças. São Paulo: Grupo Aché, 1947.

Record, 1984. - Use a passagem subterrânea. Rio de Janeiro:

Ninho de Cobras. Rio de Janeiro: Topbooks, 1997.

LÉVY, P. Cibercultura. São Paulo: Ed. 34, 1999.

LIMA, L. C. Mimese e modernidade formas das sombras. 2. ed. São Paulo: Paz e Terra, 2003.

LUCAS, C. R. "As representações da cidade no discurso literário: a rua de Clarice Lispector". In: A cidade atravessada: os sentidos públicos no espaço urbano. Campinas: Pontes, 2001. MATTELART, A. \& NEVEU, E. Estudo do romance. Lisboa: Almedina, 2004. 
RAMA, Á. Transculturação na narrativa latino-americana. Caderno de Opinião, 2. Rio de Janeiro: 1975. . A cidade das letras. São Paulo: Ed. Brasiliense, 1984.

REMEDI, G. Ciudad letrada: Angel Rama y la espacialización del análisis cultural. In: MORAÑA, M. (Org.). Angel Rama y los estudoslatinoamericanos. Pittsburgh-USA: Universidad de Pittsburgh, 1997. (Série Críticas).

PERRONE-MOISÉS, L. Texto, crítica, escritura. São Paulo: Martins Fontes, 1985.

ROLNIK, R. O que é cidade? São Paulo: Brasiliense, 1988. SOARES, A. Gêneros literários. São Paulo: Ática, 2001. TELES, G. M. O melhor de Lêdo Ivo. In: IVO, L. Lêdo Ivo: melhores crônicas. São Paulo: Global, 2004. 